\title{
CONTRIBUIÇÃO AO ESTUDO DAS ROCHAS VULCÂNICAS DA BACIA DO PARANA NA REGIÃO DE SANTA MARIA, RS*
}

\author{
PEDRO LUIZ SARTORI**, CARLOS MACIEL FILHO** e \\ EGYDIO MENEGOTTO**
}

\begin{abstract}
The volcanic rocks which occur in the southern part of the Parana basin, in Santa Maria region, Rio Grande do Sul, Brazil, are piled up in four lava flows with intertrapp sandstones and some related sills. Their radiometric age varies between $118-123$ m.y.

Descriptions of the structural aspects of the flows are made, likewise a careful study of the mineralogy and petrography in several samples collected in different positions and localities where occur each flow.

The lava flows are characterized by differences in composition which helped the identification of the stratigraphic position of each one of them.

Modal composition indicated a basalt to andesite composition for the three lower lava flows. Normative compositions, howewer, indicated more differentiated facies - latites and trachybasalts. Differences are due to unidentified mineralogical phases present in the matrix of the rocks,

The fourth upper flow, which shows the largest thickness and horizontal distribution, presents two different textural facies: a vitrophiric one and the other a granophiric. Normative composition indicated a dellenitic nature for the former one and a riolitic one for the latter.

The rocks follow the general trend known for the basaltic rocks of the Parana basin but the upper flow is established as the most differentiated already found in the magmatic province.
\end{abstract}

INTRODUÇÃO Neste trabalho são apresentados os resultados obtidos no campo e no laboratório sobre a natureza dos derrames de lava pertencentes à Bacia do Paraná, que ocorrem em Santa Maria, Estado do Rio Grande do Sul.

O levantamento geológico realizado visou principalmente situar as litologias que compõem a Formação Serra Geral, bem como estabelecer a estratigrafia dos derrames. Desta forma, os sedimentos subjacentes não foram individualizados. A região mapeada, originalmente na escala 1:25000, situa-se no rebordo sul do Planalto Meridional Brasileiro e abrange uma área em torno de $200 \mathrm{~km}^{2}$, cujas coordenadas estão na Fig. 1.

A região de Santa Maria vem sendo objeto de uma série de trabalhos e referências sobre a sua geologia, na sua quase totalidade no entanto voltados para feições paleontológicas e estratigráficas. Com relação aos derrames basálticos, os primeiros estudos nessa região foram feitos por F. Von Huene e R. Stahlecker, por ocasião de uma expedição cien. tífica ao sul do país, realizada entre julho de 1928 e abril de 1929. Leinz (1949), baseado nas descrições desses autores, fez também referências aos derrames em Santa Mariá.

Menegotto et al. (1968) caracterizaram uma seqüência sedimentar, por eles denominada Formação Tupanciretã, cobrindo os derrames basálticos ao norte do município de Santa Maria e delimitando o topo da Formação Serra Geral na região. Finalmente, Bortoluzzi (1971) publicou extenso trabalho sobre as formações sedimentares da região, incluindo suas relações com as rochas vulcânicas.

Geomorfologicamente, as lavas apresentam-se como rochas mantenedoras do rebordo do planalto e de alguns morros testemunhos, alcançando altitudes de $420-470 \mathrm{~m}$. Em alguns locais, como no cerro que ocorre ao norte da cidade, a rocha mantenedora é constituída por espessa camada de arenito intertrap (Foto 1).

* Com auxilio da Fundação de Amparo à Pesquisa do Estado do Rio Grande do Sul (FAPERGS)

**Departamento de Geociências da Universidade Federal de Santa Maria, Santa Maria, RS 


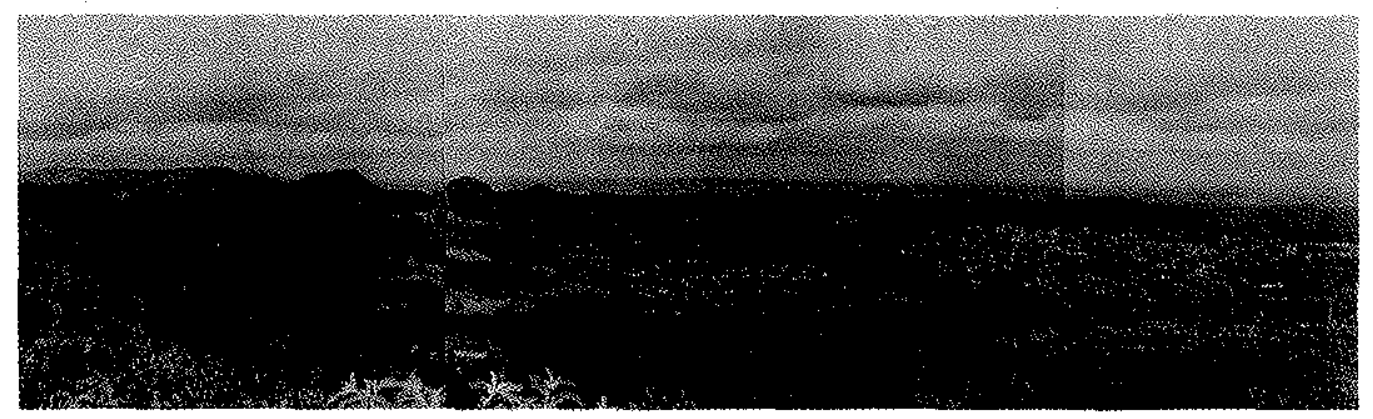

Foto 1 - Vista geral de Santa Maria, vendo-se à esquerda, ao norte da cidade, as escarpas do Planalto Meridional e, no fundo, ao sul, os morros testemunhos

Do ponto de vista geológico, a região investigada é constituída de sedimentos da Formação Santa Maria, aos quais se sobrepõem discordantemente os sedimentos da Formação Botucatu. Segundo Bortoluzzi (1971), esses sedimentos caracterizam, respectivamente, fácies fluvial e eólico. Cobrindo essa sequêencia, aparecem os derrames de lavas com arenitos intertraps da Formação Serra Geral. Depósitos sedimentares mais recentes estão representados por terraços e aluvióes fluviais, e depósitos de talude. As falhas existentes são normais, com direção dominante NW, e mais raramente NE, conforme pode ser observado na Fig. 1. Algumas formam faixas de $20 \mathrm{~m}$ de largura, contendo brecha cimentada por opala. A atitude das camadas é horizontal ou sub-horizontal, notando-se, na base do terceiro derrame um mergulho para SE.

METODOLOGIA As tarefas executadas consistiram essencialmente em trabalhos de campo e em estudos de laboratório. A fase inicial envolveu a elaboração de um mapa litológico da Formação Serra Geral, abrangendo a região escolhida. Para tanto, foram utilizadas fotografias aéreas, na escala 1:25000, dos Serviços Aerofotogramétricos Cruzeiro do Sul S.A., um mosaico dessas fotografias, e os mapas topográficos das Folhas de Santa Maria e de Camobi da D.S.G. do Ministério da Guerra, na escala 1:50000.

Afora os trajetos realizados ao longo das estradas, foram os caminhamentos ao longo das íngremes subidas do rebordo da Serra Geral, até o topo, que possibilitaram o estabelecimento da estratigrafia dos derrames. As altitudes foram determinadas através de dois altímetros tipo Paulin.

A descrição macroscópica das amostras de rochas, coletadas em várias partes de cada derrame ao longo das subidas da serra, foi feita com lupas binoculares, e o estudo óptico, em lâminas delgadas, com o auxílio de microscópio polarizante equipado com platina universal, contador de pontos e demais acessórios. Com isso foi possível caracterizar-se a textura, a composição, o tamanho e a percentagem dos constituintes mineralógicos.

A determinação do plagioclásio, um dos constituintes mais importantes dessas rochas, foi feita a partir do estudo de cristais geminados. Recorrendo-se à técnica da platina universal, assim como empregando-se uma série de estereogramas e gráficos, foi possível conseguir-se uma análise estatística dos valores e a identificação dos tipos de geminação.

Para a verificação do tipo de geminação, usou-se, principalmente, os estereogramas perpendiculares ao eixo $Y$, com as curvas de migração dos pólos dos planos cristalográficos e dos eixos de hemitropia normais (Burri et al., 1967).

$\mathrm{Na}$ determinação da natureza do plagioclásio, além dos estereogramas citados, foram empregadas também as curvas dos ângulos entre as direções ópticas correspondentes dos indivíduos geminados (Burri et al., 1967), as curvas dos ângulos entre $X, Y$ e o eixo do ge- 
minado (Slemmons, 1962) e, eventualmente, a curva do ângulo dos eixos opticos 2V (Burri et al., 1967).

O estado estrutural dos plagioclásios, classificando-os como plutônicos ou vulcânicos, foi determinado com o auxílio das curvas de Slemmons (1962). Como salientado por Rüegg (1972), essa propriedade pode ter importância no tocante à história térmica das rochas, servindo o método para a avaliação das relações de ordem e desordem existentes nos plagioclásios. Segundo Slemmons (1962), as estruturas de transição deveriam aparecer em plagioclásios de intrusões hipoabissais.

A constatação da presença de feldspatos alcalinos foi possível graças ao emprego da técnica da coloração em que a lâmina de rocha é mergulhada em cobalto nitrito de sódio, preparado na hora, a partir de uma solução de nitrito de sódio juntada a uma solução acética de cobalto.

As análises químicas quantitativas das amostras de rocha foram feitas no Instituto de Geociências da Universidade Federal do Rio Grande do Sul e os cálculos petroquímicos no Núcleo de Processamento de Dados da Universidade Federal de Santa Maria, com o auxílio de um computador eletrônico IBM-1130.

A idade absoluta de algumas amostras das rochas vulcânicas de Santa Maria foi determinada no Centro de Pesquisas Geocronológicas da Universidade de São Paulo, uti* lizando-se o método potássio-argônio.

ESTRATIGRAFIA DOS DERRAMES A Formação Serra Geral está representada por uma sucessão de derrames de lavas, de natureza basáltica, associados a arenitos intertraps.

Von Huene e Stahlecker (1931) descreveram as principais feições observadas ao longo da ferrovia que vai de Santa Maria a Pinhal, num perfil de $18 \mathrm{~km}$ de extensão. Calcularam de sete a oito intercalaçốes de arenito entre os derrames basálticos. Leinz (1949), baseado nas descrições de Von Huene e Stahlecker (1931), afirmou que, em Santa Maria, encontram-se, no mínimo, oito derrames e sete intercalações de arenitos, variando de $30 \mathrm{~cm}$ a $7 \mathrm{~m}$ de espessura.

Refazendo os perfis citados anteriormente, e realizando inúmeros outros através de caminhamentos ao longo das encostas da Serra Geral, constatou-se que, na região de Santa Maria, existem quatro derrames de lava e três arenitos intertraps. As correlações para o estabelecimento da estratigrafia foram auxiliadas pelas análises petrográficas de laboratório.

Os três primeiros derrames, cada um a seu turno, preencheram vales de uma paleotopografia acidentada e, por isso, não constituem camadas contínuas, ocorrendo sim na forma de línguas e cunhas. $O$ primeiro assenta-se sobre os arenitos eólicos da Formação Botucatu. $\mathrm{O}$ segundo e o terceiro repousam diretamente sobre as intercalações de arenito ou mesmo sobre a Formação Botucatu, quando o primeiro derrame ou os dois primeiros, respectivamente, estão ausentes. $\mathrm{O}$ quarto derrame cobriu toda a paleotopografia e forma uma camada de espessura variável, mas, geralmente, grande. Por essa razão, é aquele que apresenta maior área de exposição.

A base do derrame inferior situa-se na altitude dos $200-250 \mathrm{~m}$ e o topo entre 275$-300 \mathrm{~m}$, com a espessura variando de 30 a $70 \mathrm{~m}$.

A base do segundo localizamse entre $280-300 \mathrm{~m}$ e o topo entre $310-325 \mathrm{~m}$, com espessura de 25 a $40 \mathrm{~m}$.

O terceiro derrame mostra sua base entre as altitudes de $300-330 \mathrm{~m}$ e o topo entre $350-380 \mathrm{~m}$, com espessura em torno de $50 \mathrm{~m}$.

Por último, a base do derrame superior está compreendida entre $350-390 \mathrm{~m}$, com o topo coincidindo com a atual topografia que, na região da encosta, varia entre $420-470 \mathrm{~m}$. 


\section{$\overrightarrow{\mathrm{E}}$}

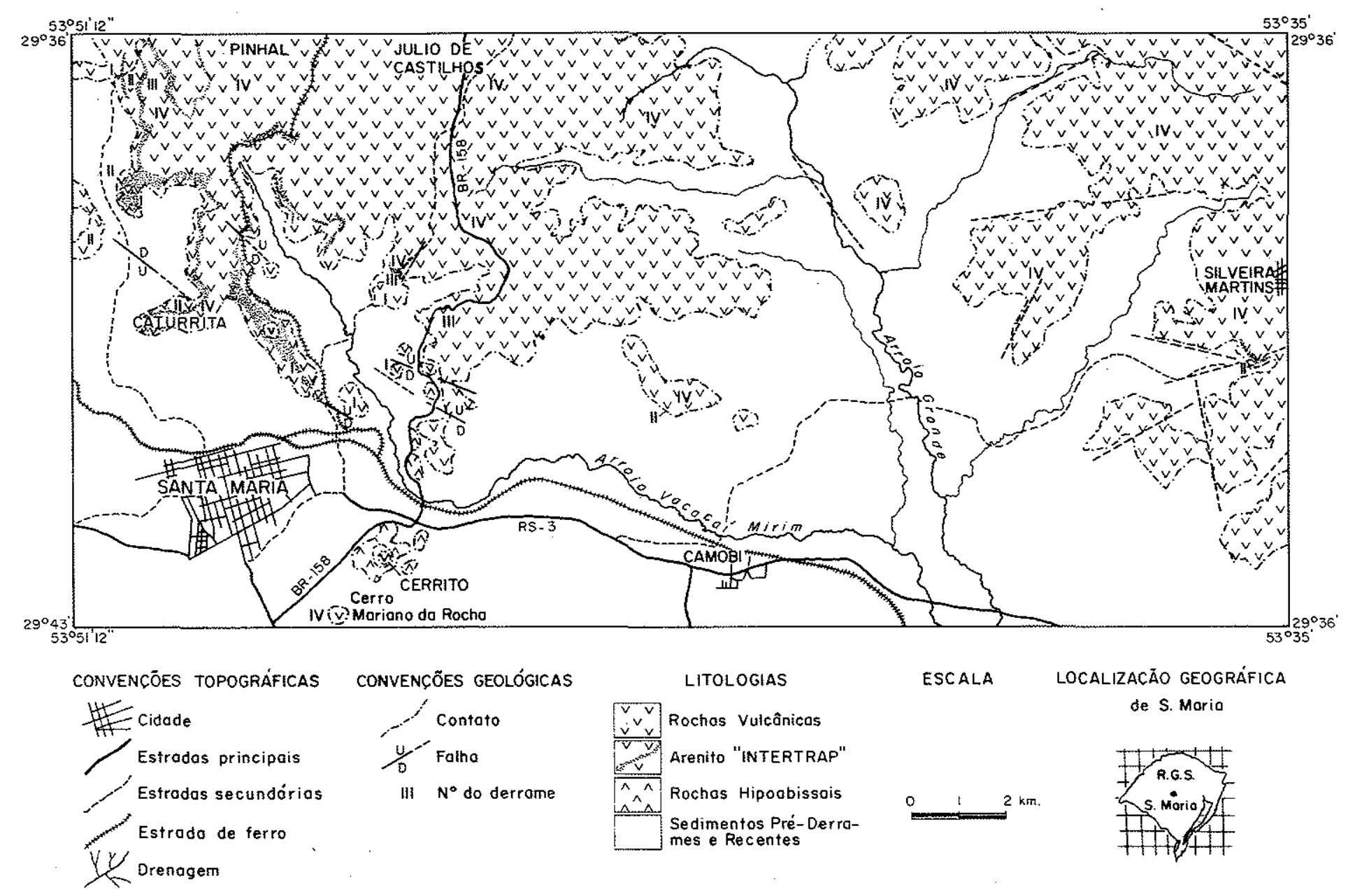

Figura 1 - Mapa litológico da Formação Serra Geral na região de Santa Maria, RS 
A espessura é sempre superior a $50 \mathrm{~m}$ podendo, inclusive, ultrapassar os $100 \mathrm{~m}$, especialmente na porção $\mathrm{NE}$ da área.

$\mathrm{Na}$ base dos derrames não foram observados fenômenos de metamorfismo de contato propriamente ditos. Ocorrem, por outro lado, em certos locais, silicificações nos arenitos imediatamente subjacentes.

INTRUSÕES Associadas às lavas, ocorrem algumas intrusões em contato com a fácies fluvial da Formação Botucatu, que podem ser vistas na BR-158 e na base do Cerrito.

Na subida da serra pela BR-158, logo após o viaduto sobre a estrada de ferro, aparece um sill entre as cotas 140 e $190 \mathrm{~m}$, tendo o contato basal inclinado para o sul de forma irregular, mas aproximadamente concordante com a estratificação das camadas sedimentares. A rocha sedimentar apresenta-se brechada na região de contato, numa faixa de aproximadamente um metro, incluindo fragmentos das encaixantes vizinhas e, mais esporadicamente, blocos de diabásio. Próximo à base, encontrou-se uma cunha de rocha sedimentar na intrusiva. A intrusiva exibe coloração cinza-escura e, petrograficamente, guarda relação com o primeiro derrame. Apresenta-se muito alterada, principalmente ao longo das diaclases, originando, assim, blocos de pedra circundados por uma matriz argilosa escura que, à primeira vista, dá o aspecto de depósito de talus. Em alguns lugares, foi possível reconhecer-se um diaclasamento paralelo horizontal e inclinado.

A outra intrusão ocorre ao norte da primeira e seu aspecto é semelhante a coluvião, sendo observados blocos irregulares e esparsos de diabásio imersos em massa argilosa. Ao sul dessa ocorrência, foram observadas diversas apófises, mostrando uma delas, no corte de estrada, a forma de lente, além de dimensões aproximadas de $8 \times 3 \mathrm{~m}$. No contato com a encaixante, apresenta uma faixa de metamorfismo de aproximadamente 15 a $20 \mathrm{~cm}$, com a metade mais próxima da intrusão exibindo coloração cinza-clara e a mais afastada, ocre, seguida pela faixa de brecha. Esporadicamente aparecem fragmentos de arenito dentro da intrusão, que se encontra quase que totalmente alterada em argila de cor parda escura, com fragmentos angulosos e esparsos pouco alterados.

Outra ocorrência, talvez relacionada com as anteriores, aparece mais ao norte, encaixada nas fácies fluvial e eólica, perturbadas por falhamentos.

Finalmente, outro corpo intrusivo ocorre na base do Cerrito e adjacências. Seu contato superior não é facilmente observado, mas pode-se notar que está dentro da fácies fluvial da Formação Botucatu. A rocha mostra-se tão fraturada quanto aquela da primeira intrusão e apresenta disjunções colunares, inclinadas e em lages. Petrograficamente, está relacionada ao segundo derrame.

GEOGRONOLOGIA A idade absoluta das rochas vulcânicas que ocorrem na região de Santa Maria foi estabelecida a partir de seis análises realizadas, pelo geólogo $\mathrm{R}$. A. Dresh, no Centro de Pesquisas Geocronológicas da Universidade de São Paulo. O método usado foi o K-Ar, descrito por Amaral et al. (1966), sendo empregadas para os cálculos as seguintes constantes:

$$
\begin{aligned}
& \lambda^{\mathrm{K}}=0,584 \times 10^{-10} \operatorname{anos}^{-1} \\
& \lambda^{\text {tot. }}=0,530 \times 10^{-9} \operatorname{anos}^{-1} \\
& \% \text { atom. } \mathrm{K}^{40} \mathrm{em} \mathbf{K}^{\text {tol. }}=1,19 \times 10^{-2}
\end{aligned}
$$

Os resultados, obtidos em rocha total, representam idades mínimas para o resfria* mento final das lavas e estão contidos na Tab. I. A descrição das amostras é feita no capítulo referente à petrografia dos derrames. 
Tabela I - Idades absolutas K-Ar de rochas vulcanicas de Santa Maria, RS

\begin{tabular}{ccccccc}
$\begin{array}{c}\text { N. } \\
\text { Campo de }\end{array}$ & SPK & Material & $\% \mathrm{~K}$ & $\begin{array}{c}\mathrm{Ar}^{40} \mathrm{rad} . \times 10^{-6} \\
\mathrm{~cm}^{3} / \mathrm{g} \mathrm{STP}\end{array}$ & $\% \mathrm{Ar}^{40}$ atm. & Idade (m.a.) \\
\hline I-1 & 2370 & Rocha total & 2,2613 & 11,47 & 10,88 & $123 \pm 8$ \\
I-6 & 2351 & Rocha total & 2,2654 & 11,04 & 86,04 & $118 \pm 22$ \\
II-8 & 2350 & Rocha total & 0,9031 & 43,94 & 78,57 & $118 \pm 8$ \\
IV-1 & 2341 & Rocha total & 1,6123 & 12,91 & 31,79 & $191 \pm 6$ \\
IV-4 & 2343 & Rocha total & 3,9729 & 19,94 & 7,86 & $122 \pm 2$ \\
IV-17 & 2338 & Rocha total & 1,9572 & 22,92 & 5,11 & $273 \pm 27$ \\
\hline
\end{tabular}

Os valores encontrados para as amostras IV-1 e IV-17 parecem estar relacionados a erros analíticos na determinação de $\mathrm{K}$, já que as análises químicas quantitativas dessas rochas forneceram valores bastante altos para $\mathrm{K}_{2} \mathrm{O}$.

Desta maneira, poder-se-ia dizer que a idade de resfriamento final dos derrames de natureza basáltica, que ocorreram na região de Santa Maria, situa-se em torno de 120 m.a.

ESTRUTURA DAS ROCHAS VULGÂNICAS Em linhas gerais, o padrão de fraturamento, devido à contração da lava durante o resfriamento, segue o modelo clássico, isto é, disjunção colunar no meio do derrame associada à disjunção horizontal, próximo à base e ao topo. Com exceção do quarto derrame, o topo dos demais é portador de vesículas e amígdalas. Por outro lado, algumas particularidades foram notadas em cada derrame.

No primeiro, observa-se uma predominância da estrutura colunar, com grande percentagem de prismas pentagonais. $\mathrm{Na}$ passagem do domínio colunar para o de lages, próximo ao topo, nota-se a presença de diaclases curvas nos locais onde a espessura do derrame é maior. Muitas fraturas verticais acham-se preenchidas por arenito silicificado vermelho, calcita ou mesmo argila. Estes minerais ocorrem também ao longo de pequenas zonas de falhamentos. A base do derrame apresenta geralmente uma camada de argila montmorillonítica, de 20 a $30 \mathrm{~cm}$ de espessura, proveniente da alteração do vidro de natureza basáltica.

No segundo derrame, o padrão de fraturamento dominante é o horizontal, mas nos locais de maior espessura, salientam-se as fraturas verticais. Muitas, com largura de 2 a $5 \mathrm{~cm}$, estão preenchidas por arenito silicificado vermelho. Por vezes, apresenta-se muito amigdalóide na base.

$\mathrm{O}$ terceiro é ocasionalmente amigdalóide e muito alterado em sua base. $\mathrm{Na}$ zona central, ocorrem fraturas verticais, inclinadas e horizontais, com predominancia das primeiras. Em certos locais, a presença de exfoliação esferoidal é comum, originando blocos arredondados; em outros, o aspecto maciço domina. $\mathrm{Na}$ extremidade superior, a estrutura em lages é abundante, o mesmo sucedendo com as amígdalas e vesículas, estando a rocha geralmente alterada e mostrando coloração amarelo-esverdeada característica. Veios de arenito silicificado preenchem fraturas de até $80 \mathrm{~cm}$ de largura.

O derrame superior apresenta uma fácies vítrea (preta e castanha) e uma fácies microcristalina (cinza-clara). A primeira sempre está associada a uma estrutura fluidal. Esta é determinada, seja pelo diaclasamen to intenso, paralelo e curvo, seja pelo alongamento e orientação das amígdalas e vesículas, por vezes muito numerosas e/ou por um fendilhamento semelhante à laminação, que delineia a forma de canais ou túneis por onde devia passar a lava. Esses canais ficam limitados por esse fendilhamento e por uma brusca ausência de amigdalas. $\mathrm{O}$ fendilhamento coloca em contato, ainda, o vidro preto, geralmente muito 
amigdalóide, com o castanho, quase sem amígdalas. A melhor exposição dessas estruturas é vista nos cortes da estrada de ferro Santa Maria - Pinhal.

Leinz (1949), medindo a direção do eixo maior das vesículas, com o intuito de inferir as direções de corrida de lavas determinou, para a zona de Pinhal, o valor de Nı $5^{\circ} \mathrm{W}$. Em razão das irregularidades dos movimentos da lava dentro de um mesmo derrame, a orientação subparalela de amígdalas alongadas em certos níveis parece indicar mais os movimentos uniformes de caráter local, de escoamento de lava, do que, propriamente, a direção geral de deslocamento do derrame como um todo.

O diaclasamento mostra uma predominância da disjunção colunar na zona central, e horizontal nas partes inferior e superior, tornando-se, muitas vezes, inclinado ou ondulado. $\mathrm{Na}$ zona da encosta da serra, é notável o espaçamento muito grande, de 1 a $2 \mathrm{~m}$ ou mais, entre as diaclases. Pela exfoliação esferoidal, os blocos contidos entre elas transformam-se em matacões, que podem formar "campos", como em Silveira Martins. Alguns blocos, por outro lado, são angulosos e quase sem capas de alteração. Em direção ao norte predomina um padrão de fraturamento horizontalizado que facilita a obtenção de lages. A fácies preta e castanho não exibe esse padrão regular, mas sim aquele diaclasamento já mencionado.

As amígdalas existentes na fácies cinza-clara não são tão freqüentes e quando ocorrem estão situadas próximo à base. Como a atual superficie topográfica situa-se sobre esse derrame, é possível que as amígdalas da sua porção tenham sido erodidas. A fácies vítrea apresenta amigdalas e vesículas, por vezes muito numerosas.

MINERALOGIA Mineralogicamente, as rochas vulcânicas que ocorrem na região de Santa Maria contêm plagioclásios, clinopiroxênios e magnetita como constituintes essenciais. Além desses minerais, verificou-se também a presença de um intercrescimento micrográfico de quartzo com feldspato alcalino, vidro vulcânico, quartzo e produtos de alteração (anfibólio e material argiloso).

Plagioclásios O estudo óptico levado a efeito possibilitou a determinação de 186 cristais de plagioclásio, distribuídos em 51 amostras. Os resultados são apresentados na Tab. II.

De conformidade com os dados obtidos, foram 11 os diferentes tipos de geminação encontrados, com uma grande predominância (91\%) dos tipos Carlsbad, Albita-Carlsbad e Albita sobre os demais, que são Albita-Ala B, Baveno direita, Baveno esquerda, Periclínio, Manebach, Aclina, Ala A e Ala B.

Observou-se que, em todos os derrames, os cristais de plagioclásio mostram-se invariavelmente zonados, em função de pequena variação na composição química durante a cristalização. Mencione-se, por vezes, a presença de uma zonação inversa, com os valores coligidos indicando diferenças de até $5,5 \%$ no teor de anortita. Segundo Jung (1963), o regime de cristalização dos piroxênios pode exercer influência no processo, repercutindo na quantidade de cálcio posta à disposição dos plagioclásios.

Ao contrário dos piroxênios, os cristais apresentam-se em geral límpidos: o hábito dominante é o ripiforme.

Piroxênios Embora sendo, juntamente com os plagioclásios, um dos principais constituintes mineralógicos da maioria das amostras estudadas, os piroxênios tiveram sua determinação muito dificultada em virtude de vários fatores, tais como: pequeno tamanho dos cristais, formas irregulares, ausência de geminação e grau de alteração. Desses, salienta-se a ausência de geminação, o que impossibilitou a utilização do método de Rüegg (1964), que usa o ângulo entre o eixo óptico $A_{1}$ e o eixo cristalografico $c$ na determinação 
Tabela II - Caracteres dos plagioclásios

\begin{tabular}{|c|c|c|c|c|c|}
\hline Amostra & $\begin{array}{c}\mathrm{N} .^{\circ} \text { de } \\
\text { determinações }\end{array}$ & $\begin{array}{c}\text { Leis de } \\
\text { geminação* }\end{array}$ & $\begin{array}{l}\text { Tipo estrutural } \\
\text { predominante** }\end{array}$ & $\begin{array}{c}\text { Campo } \\
\text { de variação }\end{array}$ & $\begin{array}{l}\text { Composição } \\
\text { média }\end{array}$ \\
\hline $\mathrm{I}-1$ & 5 & $\mathrm{C}, \mathrm{A}$ & V & $50,0-60,0$ & 55,3 \\
\hline $\mathrm{I}-2$ & 5 & $\mathrm{~A}, \mathrm{AC}, \mathrm{C}$ & V & $49,0-68,0$ & 56,0 \\
\hline I-3 & 5 & $\mathrm{~A}, \mathrm{Bl}, \mathrm{M}, \mathrm{AHb}$ & $\mathrm{P}, \mathrm{V}$ & $48,0-55,0$ & 51,2 \\
\hline $1-4$ & 4 & $\mathrm{AC}, \mathrm{A}, \mathrm{C}$ & $\mathrm{V}, \mathrm{T}$ & $37,5-50,0$ & 44,7 \\
\hline $1-5$ & 5 & $\mathrm{C}, \mathrm{AC}$ & $\mathrm{V}, \mathrm{T}$ & $49,0-53,0$ & 51,1 \\
\hline$x-6$ & 5 & $\mathrm{C}, \mathrm{A}, \mathrm{AC}$ & $\mathrm{V}, \mathrm{T}$ & $52,0-57,0$ & 54,0 \\
\hline I-7 & 5 & $\mathrm{AC}, \mathrm{A}$ & $T, V$ & $54,0-59,5$ & 56,8 \\
\hline $\mathrm{l}-8$ & 5 & $\mathrm{C}, \mathrm{AC}, \mathrm{A}$ & $\mathrm{V}, \mathrm{T}$ & $51,0-55,0$ & 52,4 \\
\hline I-9 & 5 & $\mathrm{AC}, \mathrm{A}$ & $\mathrm{V}, \mathrm{T}$ & $46,0-52,5$ & 49,5 \\
\hline$I-10$ & 5 & $\mathrm{C}, \mathrm{AC}$ & $\mathrm{V}, \mathrm{T}$ & $25,0-52,0$ & 42,2 \\
\hline I-11 & 5 & $\mathrm{AC}, \mathrm{C}, \mathrm{A}$ & V & $46,0-57,0$ & 52,2 \\
\hline $\mathrm{I}-12$ & 5 & $\mathrm{~A}, \mathrm{C}$ & $\mathrm{P}, \mathrm{V}$ & $45,5-75,0$ & 57,5 \\
\hline $\mathrm{I}-13$ & 5 & $\mathrm{AC}, \mathrm{C}$ & $\mathrm{T}, \mathrm{V}$ & $40,0-57,0$ & 50,6 \\
\hline $1-14$ & 2 & $\mathrm{C}, \mathrm{AC}$ & V & $50,0-55 ; 0$ & 52,5 \\
\hline $\mathrm{I}-15$ & 5 & $\mathrm{AC}, \mathrm{C}, \mathrm{A}$ & $\mathrm{V}, \mathrm{P}$ & $44,0-59,0$ & 53,0 \\
\hline $1-16$ & 2 & $\mathrm{C}, \mathrm{A}$ & V & $39,0 \sim 60,0$ & - \\
\hline II-1 & 2 & $\mathrm{~A}$ & $\mathbf{P}$ & $65,0-65,0$ & 65,0 \\
\hline II-2 & 5 & $\mathrm{C}, \mathrm{AC}$ & $\mathrm{V}, \mathrm{P}$ & $51,5-64,0$ & 56,5 \\
\hline II -4 & 3 & $\mathrm{C}, \mathrm{AHb}, \mathrm{Ha}$ & $\mathrm{P}, \mathrm{T}$ & $45,0-73,0$ & 55,6 \\
\hline II -5 & 5 & $\mathrm{C}, \mathrm{AC}, \mathrm{A}, \mathrm{AHb}$ & $\mathrm{V}$ & $15,5-77,0$ & 51,5 \\
\hline II-6 & 2 & A & $\mathrm{V}$ & $30,0-65,0$ & - \\
\hline II-7 & 4 & $\mathrm{~A}, \mathrm{AC}, \mathrm{Acl}$ & V & $30,0-80,0$ & 64,0 \\
\hline III-8 & 4 & $\mathrm{~A}, \mathrm{C}, \mathrm{AHb}$ & $\mathrm{T}$ & $56,0-71,0$ & 65,2 \\
\hline II-9 & 4 & $\mathrm{C}, \mathrm{AC}$ & $\mathrm{P}, \mathrm{T}$ & $53,0-74,0$ & 67,0 \\
\hline II-10 & 5 & $A, C$ & $\mathrm{P}, \mathrm{V}$ & $60,0-76,5$ & 69,5 \\
\hline
\end{tabular}

* Leis de geminação

$$
\begin{array}{ll}
\mathrm{A}=\text { Albita } & \mathrm{Ha}=\text { Ala } \mathrm{A} \\
\mathrm{AC}=\text { Albita-Carlsbad } & \mathrm{Hb}=\text { Ala } \mathrm{B} \\
\mathrm{Acl}=\text { Aclina } & \mathrm{AHa}=\text { Albita-Ala } \mathrm{A} \\
\mathrm{Bl}=\text { Baveno esquerda } & \mathrm{AHb}=\text { Albita-Ala } \mathrm{B} \\
\mathrm{Br}=\text { Baveno direita } & \mathrm{M}=\text { Manebach } \\
\mathrm{C}=\text { Garlsbad } & \mathrm{P}=\text { Periclinio }
\end{array}
$$

da composição da augita. Em virtude dessas dificuldades, a imprecisão das determinações teve de ser compensada por um estudo estatístico. Para tanto, foi determinado, na medida do possivel, com a platina universal, o ângulo de extinção $Z \wedge c$, em seçz̃es segundo (010), bem como o ângulo $2 V$. Os resultados estão contidos na Tab. III. Conforme pode ser observado, em várias amostras foi possível, tão somente, a medida do valor angular de $Z \wedge c$. Considerando os valores obtidos, augita parece ser a espécie predominante, ocorrendo subordinadamente pigeonita.

Quanto à forma, os cristais de piroxênio são granulares, arredondados e, menos con mumente, prismáticos. Nos maiores, às vezes, estão presentes inclusões de magnetita. Em certos casos, principalmente em amostras do primeiro e terceiro derrames, os grãos de piroxênio tendem a concentrar-se em torno de cristais maiores de magnetita.

Outros minerais Em todos os derrames, a magnetita é comumente euédrica, aparecendo na forma de octaedros e cubos e, mais raramente, como cristais esqueléticos. 


\begin{tabular}{|c|c|c|c|c|c|}
\hline Amostra & $\begin{array}{c}\mathrm{N} .^{\circ} \text { de } \\
\text { determinações }\end{array}$ & $\begin{array}{c}\text { Leis de } \\
\text { geminação* }\end{array}$ & $\begin{array}{l}\text { Tipo estrutural } \\
\text { predominante** }\end{array}$ & $\begin{array}{c}\text { Campo } \\
\text { de variação }\end{array}$ & $\begin{array}{c}\text { Composição } \\
\text { média }\end{array}$ \\
\hline III-1 & 7 & $\mathrm{C}, \mathrm{A}$ & $\mathrm{V}, \mathrm{T}$ & $30,0-57,0$ & 43,7 \\
\hline III-2 & 4 & $\mathrm{C}, \mathrm{AHb}$ & V & $45,0-57,0$ & 52,5 \\
\hline $111-3$ & 2 & $\mathrm{AC}$ & $\mathrm{T}$ & $45,0-50,0$ & 47,5 \\
\hline III-4 & 3 & $\mathrm{AC}, \mathrm{C}$ & $\mathrm{V}, \mathrm{T}$ & $43,0-63,0$ & 51,0 \\
\hline III-5 & 2 & $\mathrm{C}, \mathrm{A}$ & $\mathrm{V}$ & $58,0-80,0$ & - \\
\hline III-6 & 2 & $\mathrm{AC}$ & $\mathrm{V}$ & $46,0-53,0$ & 49,5 \\
\hline III-7 & 3 & $\mathrm{AC}, \mathrm{A}, \mathrm{Br}$ & $\mathrm{P}, \mathrm{V}$ & $53,0-60,0$ & 57,6 \\
\hline III- 8 & 2 & $\mathrm{C}, \mathrm{A}$ & $\mathrm{V}, \mathrm{P}$ & $45,0-60,0$ & - \\
\hline III-9 & 9 & $\mathrm{C}, \mathrm{AC}, \mathrm{A}, \mathrm{P}$ & $\mathrm{V}, \mathrm{T}$ & $33,0-59,0$ & 49,2 \\
\hline III-10 & 2 & $\mathrm{C}, \mathrm{AC}$ & $\mathrm{V}, \mathrm{T}$ & $51,0-51,0$ & 51,0 \\
\hline III-1I & 5 & $\mathrm{AC}, \mathrm{C}, \mathrm{A}$ & V & $55,0-60,0$ & 58,0 \\
\hline III-12 & 2 & $\mathrm{~A}$ & $\mathrm{~V}$ & $56,5-59,0$ & 57,7 \\
\hline III-13 & 6 & $\mathrm{C}, \mathrm{AC}, \mathrm{A}$ & $T$ & $42,0-57,0$ & 51,8 \\
\hline III-14 & 2 & $\mathrm{C}$ & V & $61,0-69,0$ & 65,0 \\
\hline III-15 & 2 & $\mathrm{C}, \mathrm{A}$ & $\mathrm{V}$ & $55,0-61,5$ & 58,2 \\
\hline IV-1 & 6 & $\mathrm{AC}, \mathrm{A}, \mathrm{C}$ & V & $20,0-60,0$ & 50,1 \\
\hline IV -2 & 5 & $\mathrm{AC}, \mathrm{C}$ & $\mathrm{v}$ & $49,0-58,0$ & 54,4 \\
\hline IV -3 & 2 & $\mathrm{C}, \mathrm{AC}$ & V & $56,0-56,5$ & 56,2 \\
\hline IV-4 & 5 & $\mathrm{~A}, \mathrm{C}, \mathrm{AC}, \mathrm{B} \mathrm{l}$ & V & $45,0-60,0$ & 54,2 \\
\hline IV -6 & 1 & $\mathrm{Hb}$ & $p$ & - & 65,0 \\
\hline IV-9 & 2 & $\mathrm{AC}, \mathrm{Br}$ & V & $2,0-32,0$ & - \\
\hline IV-10 & 2 & $\mathrm{AC}$ & V & $30,0-58,0$ & - \\
\hline IV -12 & 1 & A & - & - & 10,0 \\
\hline IV-16 & 1 & $\mathrm{Br}$ & $\mathbf{P}$ & - & 10,5 \\
\hline IV-17 & $i$ & $\mathrm{AHb}$ & $p$ & - & 9,5 \\
\hline
\end{tabular}

**Tipo estrutural predominante

$$
\begin{aligned}
& \mathrm{P}=\text { Plutônico } \\
& \mathrm{T}=\text { Transiçåo } \\
& \mathrm{V}=\text { Vulcânico }
\end{aligned}
$$

O anfibólio, de origem secundária, com pleocroísmo $X=$ amarelo-esverdeado, $Y=$ = castanho e $Z=$ castanho-escuro, foi reconhecido apenas no derrame superior. Sua determinação óptica tornou-se extremamente difícil em virtude do pequeno tamańho dos cristais e, também, da pequena quantidade presente. Contudo, medidas realizadas com a platina universal forneceram valores entre $8^{\circ}$ e $10^{\circ}$ para $Z \wedge c$, o que leva a supor tratar-se de uma hornblenda basáltica.

Os feldspatos alcalinos, quando presentes, possuem pequenas dimensões e formas irregulares. Ocorrem intercrescidos com o quartzo, sendo, por isso, impossivel a realização de medidas opticas visando à determinação da espécie. A constatação de sua presença, assim como a sua quantificação na rocha, foi facilitada pelo emprego do método colorimétrico com o cobalto nitrito de sódio.

Quartzo está quase sempre presente, aparecendo isolado, quando exibe formas irregulares, ou então em intercrescimento com o feldspato alcalino. 
Tabela III - Medidas ópticas de piroxênios

\begin{tabular}{|c|c|c|c|c|c|c|c|c|c|c|c|}
\hline \multicolumn{3}{|c|}{$1 .^{\circ}$ derrame } & \multicolumn{3}{|c|}{$2 .^{\circ}$ derrame } & \multicolumn{3}{|c|}{$3 .^{\circ}$ derrame } & \multicolumn{3}{|c|}{$4 .^{\circ}$ derrame } \\
\hline Amostra & $Z \wedge c$ & $2 V$ & Amostra & $Z \wedge c$ & $2 V$ & Amostra & $Z \wedge c$ & $2 V$ & Amostra & $Z \wedge c$ & $2 V$ \\
\hline I-1 & $38^{\circ}$ & $45^{\circ}$ & II-1 & $42^{\circ}$ & - & III-1 & $54^{\circ}$ & $38^{\circ}$ & IV-1 & $38^{\circ}-45^{\circ}$ & - \\
\hline $1-3$ & $38^{\circ}$ & $50^{\circ}$ & II -2 & $24^{\circ}$ & $\ldots$ & III-2 & $46^{\circ}$ & $70^{\circ}$ & IV-2 & $40^{\circ}$ & - \\
\hline $\mathrm{I}-4$ & $54^{\circ}$ & $60^{\circ}$ & II- 4 & $40^{\circ}$ & - & III-3 & $58^{\circ}$ & - & IV-4 & $54^{\circ}$ & - \\
\hline$I-5$ & $40^{\circ}$ & - & II-7 & $47^{\circ}$ & - & III-4 & $47^{\circ}$ & $0^{\circ}$ & IV-7 & $39^{\circ}$ & - \\
\hline I-6 & $37^{\circ}$ & - & II-8 & $40^{\circ}$ & - & III-5 & $53^{\circ}$ & $60^{\circ}$ & IV-10 & $42^{\circ}$ & - \\
\hline I-7 & $45^{\circ}$ & - & II -9 & $36^{\circ}$ & - & $111-6$ & $42^{\circ}$ & - & IV -13 & $43^{\circ}$ & - \\
\hline $1-8$ & $46^{\circ}$ & - & 11- 10 & $65^{\circ}$ & $66^{\circ}$ & III-7 & $45^{\circ}$ & $28^{\circ}$ & IV -14 & $35^{\circ}$ & - \\
\hline $1-9$ & $48^{\circ}$ & - & & & & III-8 & $48^{\circ}$ & - & IV -16 & $44^{\circ}$ & - \\
\hline $1-10$ & $52^{\circ}$ & $48^{\circ}$ & & & & III-9 & $49^{\circ}$ & -_ & & & \\
\hline I-11 & $42^{\circ}$ & - & & & & HII-10 & $58^{\circ}$ & $70^{\circ}$ & & & \\
\hline $\mathrm{I}-12$ & $55^{\circ}$ & $36^{\circ}$ & & & & III-11 & $48^{\circ}$ & - & & & \\
\hline $1-13$ & $50^{\circ}$ & $\ldots$ & & & & III-12 & $30^{\circ}$ & - & & & \\
\hline $\mathrm{I}-14$ & $52^{\circ}$ & $43^{\circ}$ & & & & III-13 & $60^{\circ}$ & $52^{\circ}$ & & & \\
\hline $1-15$ & $50^{\circ}$ & - & & & & III-14 & $40^{\circ}$ & - & & & \\
\hline I- 16 & $57^{\circ}$ & $61^{\circ}$ & & & & III-15 & $64^{\circ}$ & - & & & \\
\hline
\end{tabular}

O vidro, quando presente, contém grande número de cristalitos, geralmente na forma de triquitos.

Como minerais de amigdalas, foram reconhecidos a calcedônia, o quartzo, a calcita, os zeólitos e as argilominerais.

PETROGRAFIA Macroscopicamente, todas as amostras examinadas são afaníticas, uniformes, maciças, exceto nas porções amigdalbides, e de coloração variada. As texturas encontradas foram divididas em sete tipos para facilitar a descrição.

Primeiro derrame A rocha que constitui este derrame apresenta geralmente uma cor cinza com tonalidades esverdeadas, avermelhadas e pardas quando alterada. Ao microscópio, salienta-se a textura do tipo intergranular. O tamanho das ripas de plagioclásio $(0,60$ a $0,27 \mathrm{~mm}$ ) é sempre superior ao dos grãos do piroxênio $(0,35 \mathrm{a} 0,15 \mathrm{~mm})$, os quais estão distribuídos caoticamente entre os primeiros. A magnetita $(0,55$ a $0,30 \mathrm{~mm})$ é invariavelmente euédrica, ocorrendo na forma de octaedros e cubos.

A quantidade de plagioclásio varia entre 30 e $62 \%$ e o histograma da Fig. 2 mostra uma predominância do tipo labradorita com teores entre 50 e $55 \%$ de An. Quanto ao estado estrutural, as maiores incidências são do tipo vulcânico. $O$ piroxênio participa também da composição da rocha, com uma percentagem entre 17 e $30 \%$, enquanto que a magnetita aparece em menor escala, com teores geralmente entre 7 e $14 \%$. O quartzo está sempre presente numa proporção inferior a $6 \%$; por outro lado, vidro de cor marrom é mais abundante, conquanto que não tenha sido identificado em duas amostras. Intercrescimento micrográfico entre quartzo e feldspato alcalino pode constituir até $8 \%$ da rocha. Minerais secundários também estão presentes, com teores de até $6 \%$, e comumente provêm da alteração do vidro e dos piroxênios. As amígdalas (de $1,14 \mathrm{~mm}$ ) consistem essencialmente em quartzo e calcita. Os dados de cada amostra estão relacionados na Tab. IV.

Adotando-se a classificação de Jung e Brousse (1959), a rocha constituinte desse derrame seria um basalto normal (10 amostras), passando, no entanto, em alguns locais, face ao aumento do teor de máficos, a um basalto melanocrático ( 3 amostras), em virtude do 
I DERRAME

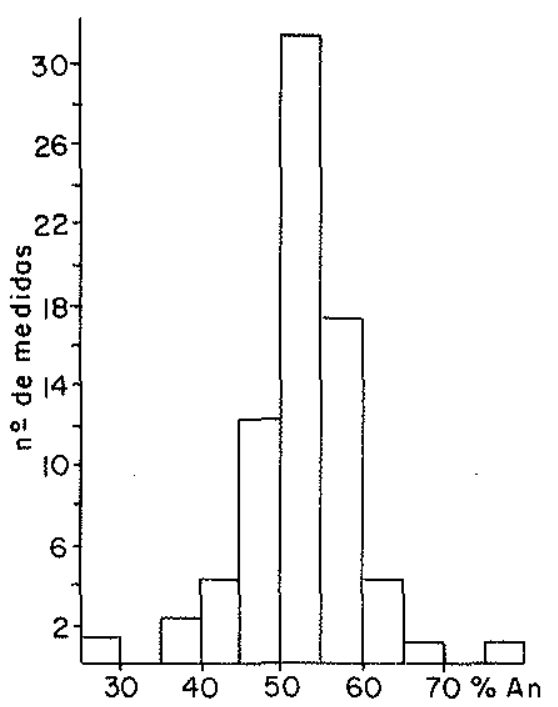

32 DERRAME

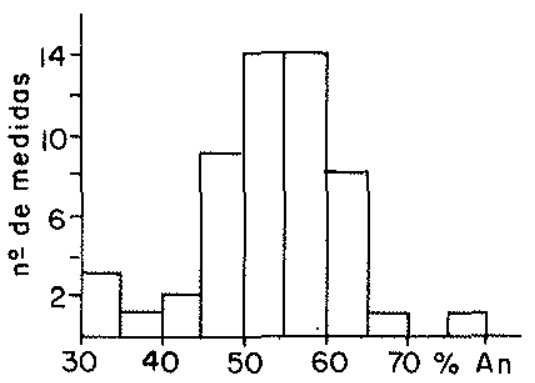

2. DERRAME

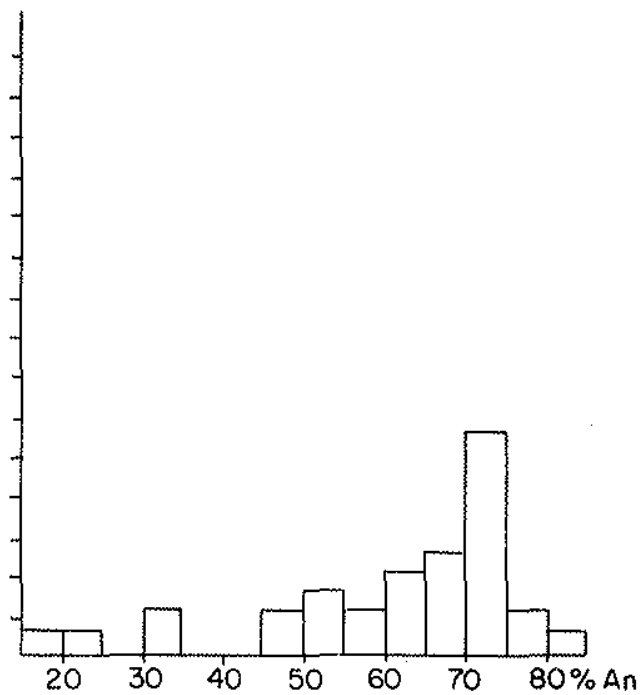

4. DERRAME

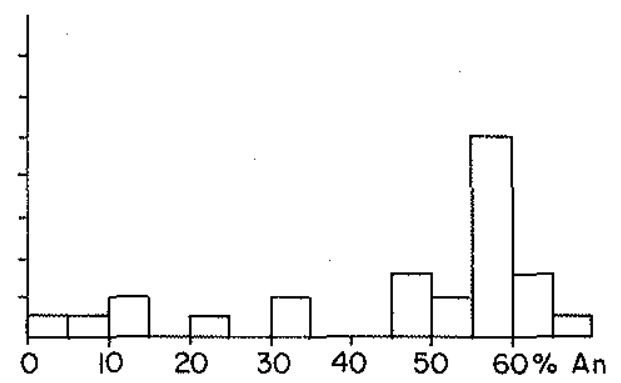

Figura 2 - Histogramas representativos dos teores de anortita dos plagioclásios

aumento do teor de plagioclásios, com $\%$ An inferior a $50 \%$ a um andesito (2 amostras) ou mesmo, pelo aumento do teor de quartzo, a um quartzo basalto ( 1 amostra).

Segundo derrame A rocha, no geral, apresenta uma cor cinza-escura a castanho-escura e, mais raramente, castanho-avermelhada. $\mathrm{Na}$ ferrovia que vai de Santa Maria a Pinhal, vê-se uma pequena ocorrência de brecha, junto ao topo, formada por fragmentos de basalto e arenito. No morro de Caturrita, esse derrame aparece totalmente alterado em uma camada argilosa de cor vermelha. Em relação ao primeiro derrame, a granulação é mais fina (piroxênio entre 0,23 a $0,13 \mathrm{~mm}$ e plagioclásio entre 0,50 e $0,13 \mathrm{~mm}$ ), predominando o tipo finamente granular, e a textura porfirítica, com pequenos fenocristais de plagio. clásio $(1,18 \mathrm{~mm})$, superiores ao dos de piroxênio $(0,52 \mathrm{~mm})$; a magnetita $($ com 0,47 a $0,11 \mathrm{~mm})$ ocorre com formas octaédricas ou como grãos irregulares.

Os teores de piroxênio são os mais elevados ( 33 a $62 \%$ ), podendo mesmo ultrapassar a quantidade de plagioclásio presente, que varia entre 28 e $50 \%$. O plagioclásio dominante é uma bytownita (Fig. 2), com teores entre 70 a $75 \%$ de An. O maior valor para o teor de anortita $(80 \%)$ foi determinado em um cristal apresentando a geminação do tipo 
Aclina. Com relação ao estado estrutural, observa-se um aumento significativo dos tipos plutônicos. Ocorre que muitas das medidas foram obtidas em pequenos fenocristais, cristalizados, provavelmente, em condições de profundidade durante a ascensão do magma.

A quantidade de magnetita varia entre 3 e $8 \%$, enquanto que o quartzo, ausente apenas em duas amostras, entre 3 e $6 \%$. Vidro é um constituinte mais raro, aparecendo

Tabela IV - Textura e mineralogia de amostras dos quatro derrames de lavas

\begin{tabular}{ccccccccc} 
Amostra & T & PL & PX & MG & QZ & VD & IM & MA \\
\hline \hline I-1 & A & 47,3 & 23,6 & 12,0 & 3,1 & 3,1 & 5,1 & 5,8 \\
I-2 & B & 30,8 & 16,8 & 48,6 & 3,7 & - & - & - \\
I-3 & A & 45,0 & 28,1 & 14,8 & 2,1 & 2,0 & 4,1 & 3,7 \\
I-4 & A & 62,2 & 20,1 & 12,4 & 1,0 & 2,2 & - & 1,8 \\
I-5 & A & 45,2 & 21,4 & 12,2 & 1,6 & 10,2 & 4,0 & 5,4 \\
I-6 & A & 52,3 & 26,5 & 7,7 & 3,3 & 2,8 & 5,2 & 2,2 \\
I-7 & A & 43,7 & 30,7 & 7,8 & 2,8 & 3,0 & 8,0 & 4,0 \\
I-8 & A & 46,4 & 18,3 & 13,7 & 6,5 & 4,1 & 6,9 & 3,9 \\
I-9 & A & 54,9 & 26,5 & 7,2 & 2,5 & - & 6,0 & 2,9 \\
I-10 & A & 39,9 & 25,5 & 9,2 & 0,7 & 12,0 & 7,0 & 6,2 \\
I-11 & A & 37,7 & 27,0 & 12,3 & 1,2 & 11,8 & 4,8 & 5,2 \\
I-12 & A & 33,9 & 28,0 & 12,0 & 0,7 & 12,2 & 7,0 & 6,2 \\
I-13 & A & 58,3 & 26,0 & 7,3 & 0,5 & 2,2 & 2,7 & 3,0 \\
I-14 & A & 43,1 & 22,4 & 12,8 & 0,9 & 15,5 & 2,0 & 3,1 \\
I-15 & A & 42,2 & 21,5 & 13,7 & 0,6 & 17,2 & 2,6 & 2,0 \\
I-16 & A & 51,0 & 22,7 & 10,8 & 3,6 & 8,7 & - & 3,0 \\
II-1 & A & 50,0 & 33,2 & 7,9 & 3,4 & - & - & 5,3 \\
II-2 & C & 49,0 & 41,0 & 6,9 & 3,1 & - & - & - \\
II-3 & D & 41,9 & 46,3 & 2,9 & 5,1 & 2,9 & - & 0,7 \\
II-4 & D & 47,3 & 41,3 & 2,9 & 3,9 & 1,9 & - & 2,5 \\
II-5 & B & 40,0 & 47,1 & 6,7 & 3,2 & - & - & 2,8 \\
II-6 & B & 47,4 & 41,7 & 3,6 & 5,1 & - & - & 1,9 \\
II-7 & B & 42,0 & 45,3 & 3,8 & 6,0 & - & - & 2,6 \\
II-8 & B & 40,9 & 56,0 & 3,0 & - & - & - & - \\
II-9 & B & 40,3 & 56,0 & 3,7 & - & - & - & - \\
II-10 & B & 28,2 & 61,8 & 6,4 & 3,6 & - & - & - \\
III-1 & A & 37,9 & 33,0 & 11,8 & $-1,9$ & 14,5 & - & 2,8 \\
III-2 & A & 41,3 & 31,9 & 10,4 & 0,5 & 12,5 & - & 3,1 \\
III-3 & A & 43,1 & 35,8 & 10,5 & 0,3 & 10,2 & - & - \\
III-4 & A & 37,4 & 36,0 & 8,7 & 1,8 & 12,9 & - & 3,2 \\
III-5 & A & 44,1 & 33,8 & 11,0 & 0,6 & 7,9 & - & 2,2 \\
\hline & & & & & & & & \\
\hline
\end{tabular}

$\mathrm{T}=$ Textura

Tipo A - Intergranular. Agregados de piroxênio sem continuidade óptica, entre ripas de plagioclásio, arranjados de maneira diversa. Grăos de magnetita com tendência euédrica e quartzo intersticial.

Tipo B - Microgranular com raros fenocristais de plagioclásio e piroxênio. Ausência de vidro.

Tipo C - Intergranular a subofitica. Hastes de plagioclásio em freqüentes agrupamentos com tendência cruciforme. Bordas ocupadas por piroxênio. Grãos de magnetita euédrica e quartzo intersticial.

Tipo D - Microgranular com fenocristais de plagioclásio e menos freqüentemente de piroxênio. Raramente vidro. 
tão somente em duas amostras, sendo o seu teor máximo da ordem de 3\%. Quartzo, calcedônia, calcita, zeólitos e argilominerais são os minerais que aparecem nas amígdalas. A descrição de cada amostra encontra-se na Tab. IV.

De conformidade com Jung e Brousse (1959), as rochas desse derrame estão classificadas no grupo dos basaltos normais (5 amostras), passando, contudo, a andesito (2 amostras), ou mesmo a melabasalto (1 amostra), tendo em vista, respectivamente, o aumento

\begin{tabular}{|c|c|c|c|c|c|c|c|c|c|}
\hline \multirow{2}{*}{ Amostra } & \multirow{2}{*}{$\mathrm{T}$} & \multicolumn{8}{|c|}{ Composição mineralógica } \\
\hline & & PL & PX & MG & $\mathrm{QZ}$ & VD & IM & $\mathrm{AF}$ & MA \\
\hline III-6 & $\mathrm{A}$ & 40,1 & 33,6 & 9,7 & 0,3 & 14,1 & - & - & 2,0 \\
\hline III-7 & A & 35,9 & 43,8 & 9,4 & 0,1 & 7,6 & - & - & 3,0 \\
\hline III-8 & A & 45,4 & 30,1 & 7,6 & - & 12,3 & - & - & 5,0 \\
\hline III-9 & $\mathrm{C}$ & 44,1 & 27,2 & 10,1 & 1,8 & 13,2 & - & - & 3,0 \\
\hline III-10 & $\mathrm{C}$ & 55,7 & 33,9 & 9,0 & 1,0 & - & 一 & - & 1,1 \\
\hline III-11 & $\mathrm{C}$ & 53,2 & 32,4 & 9,5 & 2,0 & 0,4 & - & - & 2,5 \\
\hline III-12 & $\mathrm{C}$ & 52,6 & 32,7 & 7,4 & 2,3 & 2,9 & - & - & 2,1 \\
\hline III-13 & A & 57,4 & 36,4 & 3,8 & 1,7 & - & - & - & 0,7 \\
\hline III-14 & A & 52,1 & 30,3 & 13,9 & 0,6 & - & - & - & 2,9 \\
\hline III- 15 & A & 45,3 & 29,6 & 4,3 & 0,7 & 14,4 & - & - & 5,4 \\
\hline IV-1 & $\mathrm{F}$ & 18,7 & 8,8 & 4,8 & - & 67,7 & - & - & - \\
\hline IV-2 & $\mathrm{F}$ & 14,5 & 8,0 & 4,3 & - & 73,2 & - & - & - \\
\hline IV -3 & $\mathrm{~F}$ & 23,9 & 4,4 & 0,4 & - & 71,1 & - & - & - \\
\hline IV-4 & $F$ & 20,2 & 1,7 & 5,0 & - & 72,9 & - & - & - \\
\hline IV-5 & $\mathbf{F}$ & 12,0 & 0,2 & 12,7 & 2,5 & 72,4 & - & - & - \\
\hline IV-6 & $\mathbf{F}$ & 18,5 & 0,8 & 6,3 & 3,0 & 71,2 & - & - & - \\
\hline IV-7 & $\mathbf{F}$ & 14,1 & 0,6 & 5,7 & 6,8 & 72,6 & - & - & - \\
\hline IV-8 & $\mathbf{F}$ & 6,0 & 2,6 & 16,6 & 3,9 & 70,7 & - & - & - \\
\hline IV-9 & G & 25,8 & 4,1 & 20,3 & 10,8 & - & 32,8 & 6,0 & - \\
\hline IV-10 & $\mathrm{G}$ & 25,0 & 3,7 & 10,5 & 8,1 & - & 42,2 & 10,3 & - \\
\hline IV-11 & $\mathrm{G}$ & 10,5 & 4,3 & 6,0 & 6,0 & - & 63,2 & 9,8 & - \\
\hline IV -12 & $G$ & 27,5 & 4,8 & 12,1 & 12,1 & - & 33,2 & 10,1 & - \\
\hline IV-13 & $\mathrm{G}$ & 17,9 & 1,7 & 11,7 & 3,5 & - & 60,0 & 5,1 & - \\
\hline IV-14 & $G$ & 12,2 & 2,3 & 20,4 & 7,2 & - & 50,4 & 7,3 & - \\
\hline IV-15 & $\mathrm{G}$ & 13,9 & 2,8 & 19,9 & 7,4 & - & 48,8 & 7,1 & - \\
\hline IV -16 & $G$ & 28,1 & 1,9 & 17,1 & 8,3 & - & 40,1 & 4,3 & - \\
\hline IV -17 & $\mathrm{G}$ & 11,5 & 2,0 & 10,4 & 4,0 & - & 68,0 & 4,0 & - \\
\hline IV -18 & $G$ & 27,8 & 1,8 & 20,6 & 5,8 & - & 42,3 & 1,6 & - \\
\hline IV-19 & $G$ & 28,3 & 1,7 & 19,2 & 7,5 & - & 40,7 & 2,5 & - \\
\hline IV -20 & $\mathrm{G}$ & 12,6 & 1,9 & 18,2 & 14,2 & - & 49,9 & 3,0 & - \\
\hline
\end{tabular}

Tipo E - Microgranular. Raros fenocristais de plagioclásio e piroxênio com tendência glomeroporfirica. Ausência de vidro.

Tipo F - Presença de microfenocristais com muito vidro marrom ou incolor entre micrólitos e cristais.

Tipo G - Microcristalina com cristais envolvidos por uma trama de intercrescimento micrográfico de feldspato alcalino e quartzo. Grãos de magnetita com tendência euédrica.

$\mathrm{PL}=$ Plagioclásio $\quad \mathrm{PX}=$ Piroxênio $\quad \mathrm{MG}=$ Magnetita $\quad \mathrm{QZ}=$ Quartzo

$\mathrm{VD}=$ Vidro $\quad \mathrm{IM}=$ Intercrescimento micrográfico $\quad \mathrm{AF}=$ Anfibólio $\quad \mathrm{MA}=$ Material argiloso

$\mathrm{I}-\mathrm{I}=1 .^{\circ}$ derrame $\mathrm{II}-1=2 .^{\circ}$ derrame $\mathrm{III}-\mathrm{I}=3 .^{\circ}$ derrame $\mathrm{IV}-1=4 .^{\circ}$ derrame 
no teor de quartzo e a diminuição da $\%$ An do plagioclásio, ou então pelo aumento da quantidade de piroxênio.

Terceiro derrame As rochas deste derrame apresentam-se, geralmente, com cor cinza a cinza-escura, e mais raramente castanho-avermelhada e preta. Quando totalmente alteradas, principalmente próximo à base e topo, mostram uma cor amarelo-esverdeada muito característica. A textura é semelhante à da rocha do primeiro derrame, com predominância do tipo intergranular, passando, em alguns casos, a subofítica. Em geral, o tamanho das ripas de plagioclásio $(0,80$ a $0,32 \mathrm{~mm})$ é maior que o dos grãos de piroxênio $(0,45$ a $0,16 \mathrm{~mm})$; magnetita $(0,59$ a $0,35 \mathrm{~mm})$ forma cristais euédricos disseminados na rocha.

A quantidade de plagioclásio varia entre 36 e $58 \%$ e mostra-se quase sempre superior à do piroxênio. $O$ histograma da Fig. 2 evidencia um predomínio do tipo labradorita, com teores entre 50 e $60 \%$ de An. Quanto ao estado estrutural, a maior incidência é do tipo vulcânico. $\mathrm{O}$ teor de magnetita varia entre 4 e $14 \%$, semelhante à quantidade presente no primeiro derrame. A proporção de quartzo é muito baixa, inferior a $2 \%$, enquanto que o vidro, com cristalitos disseminados na forma de triquitos e, mais raramente, escopulitos, ocorre em teores de até $14 \%$. As amígdalas, quando presentes, são formadas de calcedônia, quartzo e calcita. Nas proximidades, da BR-158, foi encontrado cobre nativo disseminado ao longo de zonas de fraturas, não chegando contudo a formar grandes concentrações. A Tab. IV mostra as composições de cada amostra.

De acordo com a classificação de Jung e Brousse (1959), esse derrame é constituído por um basalto normal (11 amostras), com pequenas variaçóes a melabasalto (2 amostras) e andesito (2 amostras).

Quarto derrame Este derrame, ao longo de sua espessura, apresenta características texturais e mineralógicas que permitern dividi-lo, em certos locais, como foi mencionado anteriormente, em duas fácies distintas; uma de caráter vítreo que, quando presente, sempre é encontrada na base do derrame, e outra microcristalina, homogênea, apresentando grande espessura e significativa distribuição horizontal.

$\mathrm{Na}$ primeira fácies, a rocha tem cor preta, brilho resinoso, passando bruscamente, em certos locais, a uma tonalidade de cor castanho-avermelhada; amígdalas são comuns junto às duas variedades. Texturalmente, contém pequenos cristais de plagioclásio $(0,47$ a $0,14 \mathrm{~mm})$ e mais raramente piroxênio $(0,23$ a $0,10 \mathrm{~mm})$, dispersos em uma matriz vítrea com grande número de cristalitos disseminados. Quanto à composição mineralógica, os plagioclásios variam entre 14 e $24 \%$, predominando o tipo labradorita com 55 a $60 \%$ de An (Fig. 2). Os piroxênios aparecem em quantidade bem inferior, com a concentração máxima não indo além de $9 \%$; a magnetita varia de 0,5 a $17 \%$, sendo o seu teor inferior a $10 \%$ na maioria das amostras. O quartzo pode estar ausente ou em quantidade inferior a $7 \%$. Por outro lado, a matriz vítrea com cristalitos é muito abundante, com teores extremos de 68 e $73 \%$. As amígdalas são formadas de calcedônia, quartzo e calcita.

$\mathrm{Na}$ outra fácies do derrame, a rocha possui cor cinza-clara uniforme e natureza microcristalina, com pequenos cristais de plagioclásio $(0,35$ a $0,13 \mathrm{~mm})$, piroxênio $(0,44$ a $0,27 \mathrm{~mm})$, anfibólio e magnetita $(0,55$ a $0,17 \mathrm{~mm})$ envolvidos por uma trama de intercrescimento micrográfico de quartzo e feldspato alcalino. Os teores de plagioclásio variam entre 11 e $28 \%$. Nesta rocha consta tou-se a presença de plagioclásios mais sódicos, inclusive oligoclásio e mesmo albita (Fig. 2). $\mathrm{O}$ valor menor encontrado, $2 \%$ de An, foi obtido num cristal exibindo geminação Baveno direita. Quanto ao estado estrutural predomina, para todo o derrame, o tipo vulcânico. Piroxênio ocorre em concentração muito baixa, inferior 
a $: 5 \%$, enquanto que magnetita pode atingir até $20 \%$; quartzo, isolado alcança até $14 \%$ do volume da rocha. Anfibólio apresenta-se comumente como pequenos grãos $(0,25 \mathrm{~mm})$ e em proporções não superiores a $10 \%$ (Tab. IV).

Schneider e Pires da Rocha (1968) descreveram uma amostra extraída de uma pedreira situada próximo à cidade de Santa Maria, pertencente, pela descrição, provavelmente a essa porção do quarto derrame. Caracterizaram-na como sendo um basalto silicificado, portador de elevado teor de quartzo secundário. $\mathrm{Na}$ realidade, as o’sservações levadas a efeito evidenciaram a presença de um intercrescimento micrográfico e não de uma silicificação secundária.

Pelas características observadas, a rocha da fácies vítrea pode ser classificada como um vitrófiro. A rocha da outra fácies, considerando-se a sua composição mineralógica e o aspecto textural, com abundância de intercrescimento micrográfico, indica que a composição do magma seria a de um líquido ácido de composição granofirica. Rosembusch in Johannsen (1933) classifica os riólitos portadores de uma matriz holocristalina composta por quartzo e feldspato intimamente intercrescidos como granófiros.

A rocha que constitui esse derrame superior, caracterizada neste trabalho, estendemse para norte abrangendo grande área da região do planalto, em sua porção central, no Rio Grande do Sul.

Os estudos petrográficos realizados mostraram-se de grande importância, no estabelecimento da estratigrafia dos derrames. Embora fenômenos de diferenciação não fossem observados ao longo de um mesmo derrame, diferenças na composição e aspectos texturais, foram verificadas, evidenciando a natureza distinta da lava que originou cada um deles.

Com base nesse estudo constatou-se que o segundo derrame recobre o Cerrito, em contato com a Formação Botucatu, na cota de $257 \mathrm{~m}$. O quarto derrame transgrediu sobre os inferiores, rumo ao sul, capeando o Cerro Mariano da Rocha, em contato com os arenitos da Formação Botucatu, na altitude de $225 \mathrm{~m}$.

Relaf̧ôes plagioclásio - piroxênio - magnetita Num confronto entre os quatro derrames, usando-se teores de plagioclásio, piroxênio e magnetita nas amostras, verifica-se ser possível distingui-los do ponto de vista mineralógico (Fig. 3).

O primeiro apresenta uma predominância de plagioclásio sobre o piroxênio; o segundo, teores mais próximos entre esses dois minerais e pequena quantidade de magnetita. No terceiro, o plagioclásio predomina, porém a quantidade de piroxênio é maior do que aquela existente no primeiro derrame, enquanto a magnetita difere apenas ligeiramente. Finalmente, o quarto derrame apresenta uma quantidade muito pequena de piroxênio e teores variados de plagioclásio e magnetita.

PETROQUIMICA Cinco análises químicas quantitativas das rochas vulcânicas da Bacia do Paraná, que ocorrem na região de Santa Maria, foram realizadas, com os resultados obtidos constando da Tab. V.

A composição normativa dessas amostras (Tab. VI) confirma o caráter supersaturado das rochas da província, estando o quartzo presente em todas elas.

Levando-se em conta o esquema de classificação apresentado por Rittmann (1963), o primeiro derrame enquadra-se no grupo dos latitos e o terceiro nos traquibasaltos, enquanto que a composição modal de ambos, como vimos anteriormente, classifica-os como basaltos com variações e andesitos. Tal fato pode estar relacionado à presença de vidro e de intercrescimentos micrográficos nesses derrames, e que não foram computados na classificação modal das amostras, em razão da impossibilidade de ser determinada a na- 


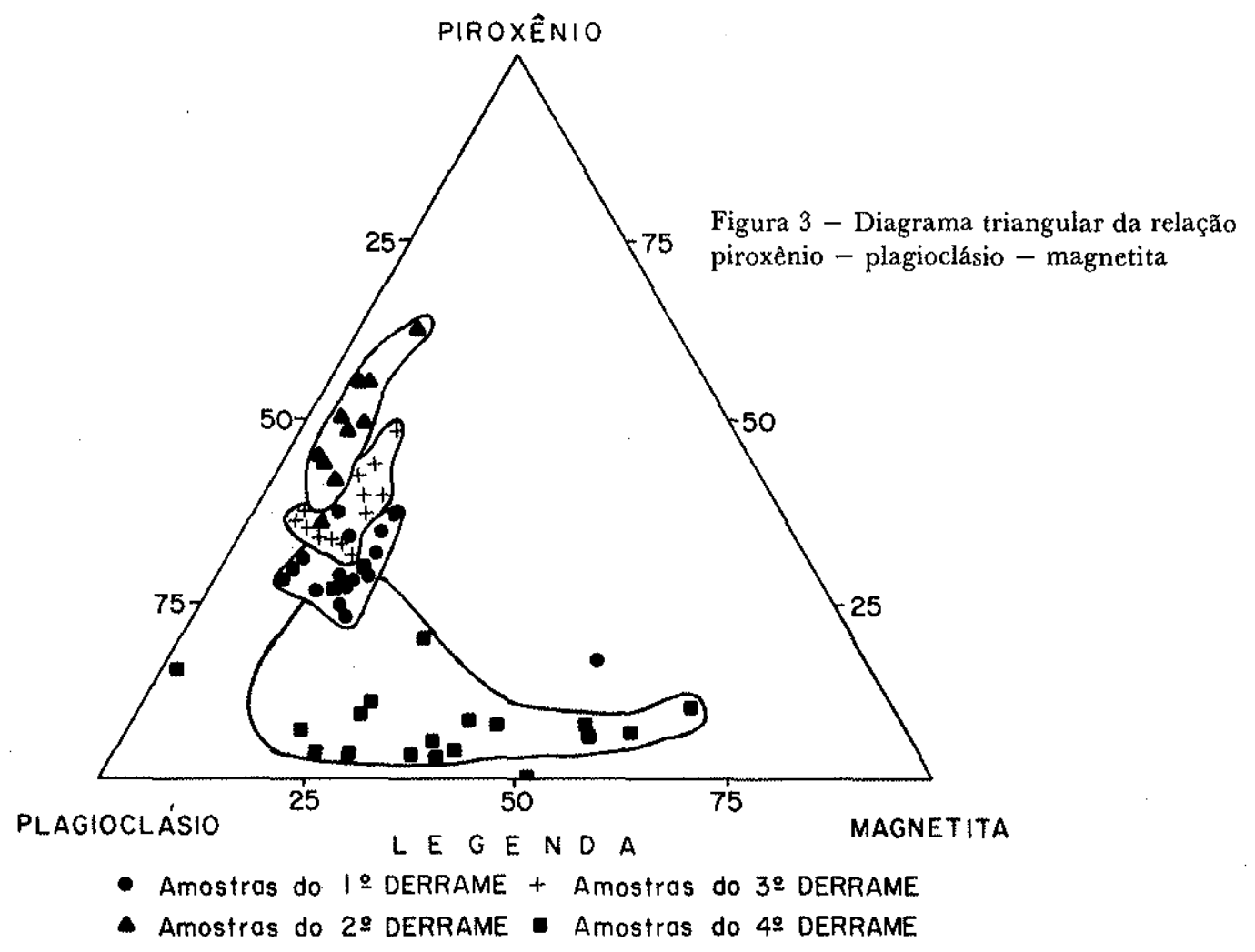

Tabela V - Análises químicas das rochas efusivas de Santa Maria, RS

\begin{tabular}{lrrrrr}
\hline & I-8 & \multicolumn{1}{c}{ I-14 } & \multicolumn{1}{c}{ III-1 } & \multicolumn{1}{c}{ IV-1 } & IV-17 \\
\hline \hline $\mathrm{SiO}_{2}$ & 55,72 & 54,48 & 51,75 & 66,89 & 67,39 \\
$\mathrm{Al}_{2} \mathrm{O}_{3}$ & 14,01 & 14,34 & 16,00 & 13,45 & 11,68 \\
$\mathrm{Fe}_{2} \mathrm{O}_{3}$ & 7,18 & 9,39 & 8,89 & 3,65 & 4,28 \\
$\mathrm{FeO}$ & 5,92 & 4,01 & 5,32 & 1,90 & 0,96 \\
$\mathrm{MnO}$ & 0,25 & 0,31 & 0,16 & 0,06 & 0,06 \\
$\mathrm{MgO}$ & 2,69 & 2,37 & 2,94 & 0,82 & 0,61 \\
$\mathrm{CaO}$ & 5,68 & 5,71 & 6,92 & 2,73 & 2,29 \\
$\mathrm{Na}_{2} \mathrm{O}$ & 2,20 & 2,33 & 2,97 & 2,46 & 2,93 \\
$\mathrm{~K}_{2} \mathrm{O}$ & 3,01 & 3,32 & 2,79 & 4,69 & 6,24 \\
$\mathrm{TiO}_{2}$ & 0,34 & 0,38 & 0,42 & 0,12 & 0,10 \\
$\mathrm{P}_{2} \mathrm{O}_{5}$ & 0,07 & 0,07 & 0,08 & 0,05 & 0,07 \\
$\mathrm{H}_{2} \mathrm{O}^{+}$ & 0,79 & 1,01 & 1,03 & 1,82 & 1,83 \\
$\mathrm{H}_{2} \mathrm{O}^{-}$ & 1,82 & 1,75 & 1,20 & 1,39 & 0,95 \\
\hline \multicolumn{1}{c}{ Total } & 99,68 & 99,47 & 100,47 & 100,03 & 99,39 \\
\hline
\end{tabular}

tureza do vidro e a proporção relativa dos constituintes desses intercrescimentos. Com relação ao quarto derrame, a norma evidencia uma composição dellenítica para a porção vítrea e tiolítica para a parte cristalina com teor mais elevado em $\mathrm{K}_{2} \mathrm{O}$.

Segundo Rüegg (1969), "uma vez admitido que os basaltos, em virtude de seu relativamente rápido processo de consolidação devem exibir composições mais próximas aos 
Tabela VI - Normas das rochas efusivas de Santa Maria, RS

\begin{tabular}{lrrrrr}
\hline & I-8 & I-14 & III-1 & IV-1 & IV-17 \\
\hline Quartzo & 15,04 & 14,67 & 6,39 & 27,82 & 23,38 \\
Ortoclásio & 17,84 & 19,72 & 16,41 & 27,71 & 37,10 \\
Albita & 18,68 & 19,82 & 25,01 & 20,81 & 24,94 \\
Anortita & 19,52 & 18,96 & 21,98 & 11,80 & 0,29 \\
Diopsídio & 6,78 & 7,05 & 9,31 & 1,12 & 3,30 \\
Hiperstênio & 8,25 & 2,67 & 4,87 & 1,90 & - \\
Wolastonita & - & - & - & - & 2,69 \\
Magnetita & 10,44 & 12,90 & 12,83 & 5,29 & 3,02 \\
Hematita & - & 0,54 & - & - & 2,22 \\
Ilmenita & 0,65 & 0,73 & 0,79 & 0,23 & 0,19 \\
Apatita & 0,17 & 0,17 & 0,19 & 0,12 & 0,17 \\
$\%$ An & 51,11 & 48,89 & 46,77 & 36,19 & 1,15 \\
\hline
\end{tabular}

magmas de origem conclui-se que, entre as rochas basálticas da Bacia do Paraná, não se operaram apenas processos de diferenciação in situ. As variedades de tipos de rochas basálticas que podem ser observadas na província, certamente em parte resultaram da consolidação a partir de um líquido magmático que ao consolidar já se apresentava diferenciado". Isso parece corresponder ao caso da região. Os derrames estudados apresentam pequenas variações de composição internamente, mas diferenças significativas entre eles, especialmente entre os três primeiros e o quarto. Neste último, a natureza do derrame leva a admitir a efusão de um magma extremamente ácido nessa porção da Bacia do Paraná.

A análise comparativa reunindo os valores obtidos para a composição dos plagioclásios, seja a partir de determinações ópticas, seja da análise normativa das rochas, possibilitou a obtenção de informações interessantes. Assim, por exemplo, para a amostra I-8, a média encontrada $(52,4 \%$ de An) aproximou-se muito do valor obtido a partir do cálculo normativo $(51,1 \%$ de $\mathrm{An})$. Isto também foi observado junto às demais amostras do primeiro e terceiro derrames. No quarto, entretanto, apareceram maiores diferenças. $\mathrm{Na}$ amostra IV-1, coletada próximo à base, a média de 50,1\% de An, obtida nas medidas opticas, está um pouco distante daquela referente à análise normativa, $36,2 \%$ de An. Essa diferença, no caso, é um fato normal, em razão do alto teor da matriz vítrea em que estão contidos os cristais de plagioclásio. Como os primeiros cristais formados são mais cálcicos (Bowen, 1928), a média do seu teor em anortita é maior do que seria se toda a parte vítrea se cristalizasse, quando então os teores seriam bem mais próximos do valor normativo encontrado. $\mathrm{Na}$ amostra IV-16, coletada na parte superior do derrame, o valor óptico de uma determinação $(10,5 \%$ de An) guarda assim uma certa correspondência com o valor normativo ( $1,2 \%$ de An). As determinações ópticas dos plagioclásios nas amos. tras dessa parte do derrame são extremamente dificeis, em razão do diminuto tamanho dos cristais e da trama de intercrescimento micrográfico em que se acham envolvidos. Contudo os resultados obtidos evidenciaram o caráter mais sódico dos plagioclásios dessa fácies.

Finalmente, vê-se que as rochas que ocorrem na região de Santa Maria acompanham o trend geral de diferenciação na província basáltica da Bacia do Paraná (Fig. 4), estabelecido por Rüegg (1969) a partir da variação dos elementos principais relativamente ao indice de Nockolds e Allen (1953). Exceção marcante representa o Ti, que apresenta valores muito baixos se comparados com aqueles obtidos por Rüegg (1969). A rocha, que constitui a parte superior do quarto derrame, aparece como o termo mais diferenciado com teores elevados em $\mathrm{Si}$ e $\mathrm{K}$ e mais baixos em $\mathrm{Mg}$, Fe, $\mathrm{Ca}$ e $\mathrm{Ti}$. 


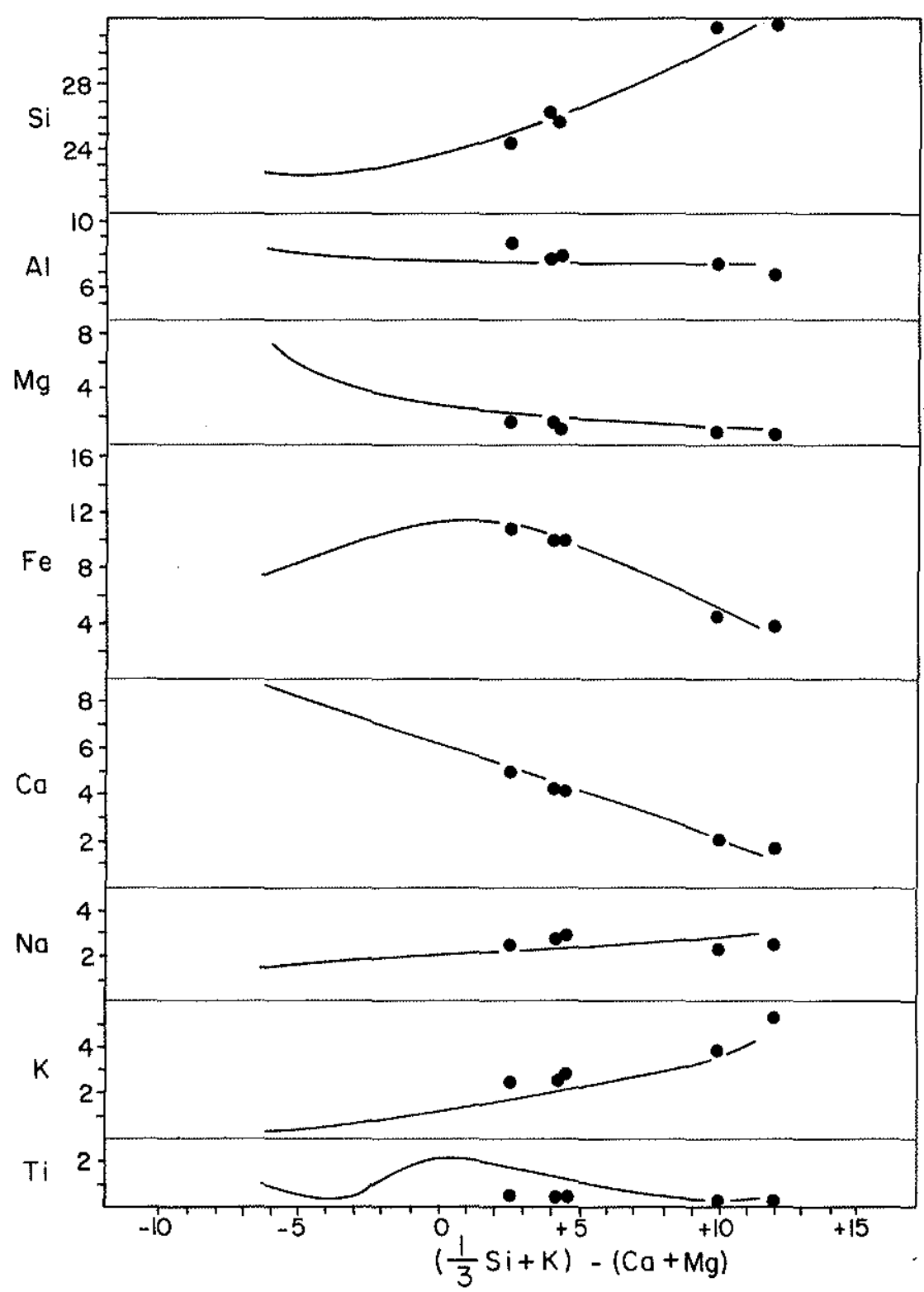

Figura 4 - Gráfico relacionando elementos principais e índice de diferenciação de Nockolds e Allen (1953). Curvas projetadas com os dados de Rüegg (1969) para as rochas basálticas da Bacia do Paraná. Os pontos referem-se às rochas de Santa Maria, RS

Dessa maneira, pode-se concluir que, até o presente momento, os derrames mais ácidos que ocorrem na Bacia do Paraná apresentam grande distribuição no topo do Planalto Meridional Brasileiro no Estado do Rio Grande do Sul, não estando somente confinados à região nordeste como admitia Schneider (1964), mas aparecendo também em sua porção central. 
Agradecimentos Os autores agradecem aos Professores Dr. Umberto G. Cordani e Dr. Nabor R. Rüegg pelo estímulo e pelas sugestões apresentadas; ao Prof. Dr. Celso de Barros Gomes pela completa revisão.

\section{BIBLIOGRAFIA}

AMARAL, G., GORDANI, U. G., KAWASHITA, K. e REYNOLDS, J. H. - 1966 - Potassium Argon ages of basaltic rocks from Southern Brazil. Geochim. Cosmochim. Acta, 30 (2): 159-189

BORTOLUZZI, C. A. - 1971 - Contribuição à geologia da região de Santa Maria, Estado do Rio Grande do Sul. Dissertação de Mestrado. Instituto de Geociências da Universidade Federal do Rio Grande do Sul (inedito)

BOWEN, N. L. - I928 - The evolution of igneous rocks. Princeton Univ. Press, Princeton

BURRI, C., PARKER, R. L. e WENK, E. - 1967 - Die optische orientierung der plagioklase. Springer Verlag, Basel

HUENE, F. V. e STAHLECKER, R. - 1931 - Observações geológicas no Rio Grande do Sul. Trad. R. Beltrão e M. Neumaier (1968). UFSM. Inst. Ciências Nat., Bol, 3: 1-62

JOHANNSEN, A. - 1933 - A descriptive petrography of the igneous rocks. Vol. IV. The University of Chicago Press, Chicago

JUNG, J. - 1963 - Précis de pétrographie. Masson et Cie, Paris.

JUNG, J. e BROUSSE, R. - 1959 - Classification modale des roches éruptives. Masson et Cie, Paris

LEINZ, V. - 1949 - Contribuiçăo à geologia dos derrames basálticos do sul do Brasil. Fac. Fil. Ciências e Letras da USP, Bol. CIII, Geologia 5: 1-61

MENEGOTTO, E., SARTOR1, P. L. e MACIEL FILHO, G. L. - 1968 - Nova seqüência sedimentar sobre a Serra Geral no Rio Grande do Sul. UFSM, ISG, Sec. Geologia, Publ. Esp. 1: $1-19$

NOCKOLDS, S. R. e ALLEN, R. - 1953 - The geochemistry of some igneous rock series. Geochim. Acta, 4: 105 142.

RITTMANN, A. - 1963 - Les volcans et leur activité. Trad. H. Tazieff. Masson et Cie, Paris

RUEGG, N. R. - $1964-$ Use of the angle $A_{1} \wedge c$ in optical determination of the composition of augite. Amer. Mineral., 49: 559-606

RÜEGG, N. R. - 1969 - Aspectos geoquímicos, mineralógicos e petrográficos de rochas basálticas da Bacia do Paraná. Tese de Doutoramento. Faculdade de Filosofia Ciências e Letras da Universidade de São Paulo (inédito)

RÜEGG, N. R. - 1972 - Plagioclásios plutônicos e vulcánicos em diabásiọ da Bacia do Paraná. Rev. Bras. Geoci., 2(1): 8-17

SLEMMONS, D. B. - 1962 - Determination of volcanic and plutonic plagioclases using a threeor four-axis universal stage. Geol. Soc. Amer., Special Paper 69: 1-64

SCHNEIDER, A.W. - 1964 - Contribuiçăo à petrologia dos derrames basálticos da Bacia do Paraná. UFRGS, Esc. Eng., Avulso 1: 1-76

SCHNEIDER, A. W. e PIRES DA·ROCHA, F.X. - 1968 - Emprego de basaltos em pavimentação rodoviária. CNPq, IPR, Publ. 433: 1×43 